\title{
Religião e capital simbólico: um estudo do "Projeto Social Pequeno Samuel", situado em Rio Grande da Serra, no Grande ABC Paulista
}

\author{
Religion and symbolic capital: study of the "Pequeno Samuel Social Project",
} located in Rio Grande da Serra, in the "Grande ABC Paulista"

\section{Claudio Pereira Noronha*}

\begin{abstract}
Resumo
Este estudo se propõe a discutir a relação entre religião e capital simbólico, com o objetivo de avaliar a capacidade das redes sociais e práticas associativas, em torno de grupos religiosos, para agregar benefícios aos seus participantes, sobretudo em sua dimensão simbólica. Para isso, são analisadas atividades realizadas pelo "Projeto Social Pequeno Samuel", uma associação ligada à Igreja Batista Central, especialmente as que se referem às práticas de educação socioambiental. As informações, para tal análise, foram obtidas através do site e estatuto da entidade, além de participação presencial em seus trabalhos. Levando em conta que a cidade possui os índices sociais menos favoráveis da região do Grande $A B C$ paulista, e, por sua importância ambiental para a mesma região - pois é constituída por uma área de proteção de mananciais -, considera-se que o conjunto de práticas realizadas pelo projeto contribui, em grande medida, para o aumento do "capital simbólico" da comunidade.
\end{abstract}

Palavras-chave: Religião. Capital simbólico. Grande ABC paulista. Rio Grande da Serra. Projeto Social Pequeno Samuel.

\begin{abstract}
The present study aims to discuss the relation between religion and symbolic capital and evaluate the capacity of the social networks and associative practices within religious groups, to aggregate some benefits to their members, especially those related to symbolic dimensions. For this purpose, we will analyze the activities done by the "Pequeno Samuel Social Project", an association of the Central Baptist Church, especially those activities related to social, environmental and educational practices. The information for this analysis were obtained from the website, from the constitutional document of the Entity, and as well from the author's participation in the social works of the Social Project. Taking into account that the city has the least favorable social indicators in the region of "Grande ABC Paulista", and also considering its environmental importance to the same region - a Watershed Protection Area - we consider that the set of practices performed by the project contributes largely to the increase of "symbolic capital" of the community.
\end{abstract}

Keywords: Religion. Symbolic Capital. Grande ABC Paulista. Rio Grande da Serra. Pequeno Samuel Social Project.

Artigo recebido em 7 de agosto de 2012 e aprovado em 4 de dezembro de 2012.

* Doutorando pelo programa em Ciências da Religião pela Universidade Metodista de SP. Integrante do grupo de pesquisa REPAL (Religião e Periferia na América Latina). País de origem: Brasil. E-mail: clpnoronha@yahoo.com.br 


\section{Introdução}

Este estudo tem por objetivo discutir a relação entre religião e capital simbólico, avaliando a capacidade das redes sociais e práticas associativas, situadas no campo religioso, para agregar "benefícios", sobretudo em sua dimensão simbólica. No âmbito deste trabalho, analisa-se o "Projeto Social Pequeno Samuel”, uma associação ligada à Igreja Batista Central, situada no município de Rio Grande da Serra, região do Grande ABC paulista.

O Grande ABC paulista, impulsionado pelo desenvolvimento industrial agraciado nas décadas de 1950 e 60, com as principais indústrias automobilísticas do país - e comercial - alavancado, principalmente, nos anos 1980 e 90, pelos shoppings e grandes redes de supermercado - é um mercado produtor e consumidor de relevância nacional. Um dos aspectos que analisados é a inserção de Rio Grande da Serra nesse contexto. Porque esse município, a despeito do local privilegiado em que se encontra, tornou-se uma cidade pouco desenvolvida?

Os estudos debruçados na "questão urbana”, analisando o surgimento das grandes cidades, vinculados à industrialização e migração, por exemplo, demonstram enorme "inequidade" na forma como foram (e ainda são) distribuídos os capitais industrial, imobiliário etc. ao longo do tempo (SANTOS, 1979; SINGER, 2002; DAMIANI, 2004). Rio Grande da Serra é um exemplo disso. Impedida de construir um "parque industrial” próprio, por suas características geográficas e sua inserção na "Legislação de Proteção aos Mananciais" (de 1976), tornou-se

dependente da estrutura orçamentária estadual e federal, distanciando-se do crescimento regional. As poucas indústrias, o pequeno comércio, além do baixo investimento do Poder Público, levaram o município aos menores índices sociais (renda, escolaridade etc.) de toda a região. O impacto dos recentes investimentos públicos ainda precisa ser mais bem avaliado.

No que diz respeito à diversidade e crescimento de práticas religiosas em Rio Grande da Serra, essas se destacam, como apontam os dados do IBGE (2012). O 
percentual de pessoas que se assumem como evangélicas $(33,83 \%)^{1}$, com destaque para os pentecostais (24,18\%), é maior que a média nacional. Contudo, outros grupos religiosos estão presentes. O catolicismo ainda é a religião professada pela maioria da população (46,05\%), e o crescimento e a organização de "grupos carismáticos”, nesse campo religioso, já podem ser observados. A presença de grupos religiosos no campo mediúnico e afro-brasileiro é mais discreta $(1,54 \%)^{2}$, seja na quantidade de adeptos, seja na forma como se apresentam (seus espaços religiosos são, em geral, destituídos de placas indicativas). A hipótese desse trabalho é que as redes e práticas religiosas contribuem, para aqueles que dela participam, na produção de um importante "capital simbólico". Esta discussão é dividida em três partes.

$\mathrm{Na}$ primeira parte se discute o baixo desenvolvimento socioeconômico de Rio Grande da Serra, principalmente quando analisado em um contexto regional. O objetivo, nesse caso, é ressaltar a importância das práticas associativas para o conjunto da população carente. A abordagem, na segunda parte, concentra-se na relação entre religião e capital simbólico. Embora não seja a questão central deste estudo, destaca-se, entre os elementos que se constituem como benefícios simbólicos, a “questão ambiental”, discussão ainda incipiente, mas que tem-se tornado relevante nas práticas associativas do município. A terceira parte está reservada para a apresentação do "Projeto Social Pequeno Samuel”, destacando suas principais atividades junto às crianças e adolescentes.

\section{Rio Grande da Serra e o Grande ABC paulista}

As décadas de 1950 e 60 têm uma importância significativa para a região do Grande ABC. Nesse período "surgem" as sete cidades que compõem sua atual

\footnotetext{
${ }^{1}$ Nesse percentual não constam a Igreja Adventista dos Sétimo Dia, Igreja de Jesus Cristo dos Santos dos Últimos Dias e as Testemunhas de Jeová, que, juntas, representam $2,87 \%$ da população.

2 É bem provável que parte dos adeptos desses grupos, principalmente do candomblé e da umbanda, que comumente também pertencem ao catolicismo, tenha se declarado "católico" no momento de responder as perguntas "sobre religião" do Censo.
} 
delimitação geográfica e intensifica-se o crescimento industrial, impulsionado pela implantação de indústrias automobilísticas como Volkswagen e Karmann-Ghia (KLINK, 2001; GARCIA, 2007). Dizemos “intensifica-se” porque em período anterior já havia indústrias na região, concentradas, principalmente, no ramo têxtil (FRENCH, 1995). Até a década de 1940, "Santo André" correspondia a todo o território que atualmente compõe o Grande ABC. Em 1944 ocorreu a primeira divisão, formando-se as cidades de Santo André e São Bernardo. Posteriormente, as sucessivas emancipações constituíram os sete municípios atuais: Santo André, São Bernardo do Campo, São Caetano do Sul, Diadema, Mauá, Ribeirão Pires e Rio Grande da Serra, este o último a se emancipar (SEADE, 2012). A localização estratégica, demarcada pela proximidade com a cidade de São Paulo (que já estava em grande expansão urbana e industrial) e o Porto de Santos, além do importante eixo ferroviário, foram elementos fundamentais para que o $\mathrm{ABC}$ se constituísse como um grande "polo industrial”.

Nesse contexto, regiões industrializadas, como São Paulo e Grande ABC, transformaram-se em fortes "centros de atração" de migrantes. Por outro lado, o pouco desenvolvimento industrial e agrícola e a falta de investimentos em infraestrutura de serviços tornaram determinadas regiões do país - exemplo marcante é o agreste nordestino - “áreas de emigração” (SINGER, 2002). O “fluxo migratório", nesse sentido, foi decisivo para o crescimento populacional dessas regiões. Contudo, ele ocorreu de maneira desordenada, visto que o crescimento das grandes cidades, no Brasil, ocorreu sem, ou com muito pouco, planejamento, resultando em cidades mal estruturadas, ou mal preparadas, para receber um número expressivo de pessoas (SANTOS, 2008).

Rio Grande da Serra, entre as décadas de 1970 e 80, apresentou, segundo dados do IBGE, um crescimento populacional (139,2\%) ainda mais expressivo que a própria região do Grande $\mathrm{ABC}(67,2 \%)$ e de São Paulo (40,9\%)3. Migrantes vindos

\footnotetext{
${ }^{3}$ Na década de 1970, Rio Grande da Serra possuía uma população de 8.397 habitantes, passando para 20.091 em 1980. Atualmente, a população é de 43.974 habitantes (IBGE, 2012).
} 
do Nordeste (especialmente da Bahia e de Pernambuco) e de Minas Gerais, buscando uma "vida melhor" e chegando à região do Grande ABC para trabalhar em suas indústrias (o sonho de muitos migrantes!), encontravam, em Rio Grande da Serra, a possibilidade de comprar terrenos mais baratos e construir sua moradia - muitas vezes através da autoconstrução.

O deslocamento de migrantes para as regiões menos centrais se tornou algo relativamente comum. A impossibilidade de absorção de todo o conjunto, do enorme, e nem sempre "qualificado" (do ponto de vista do capital), contingente de mão de obra vindo das regiões de "expulsão" (SINGER, 2002), fez com que parte se acomodasse nas regiões mais afastadas. De fato, esse é um período em que a parcela da população em situação socioeconômica precária viu-se obrigada, por falta de opção de moradia, a ir morar em favelas ou bairros distantes dos principais centros. Isso ocasionou relativa "segregação" ou "isolamento", considerando que os melhores empregos e serviços prestados concentram-se nas regiões centrais (CALDEIRA, 2000; MARQUES; TORRES, 2004). Todo esse processo não ocorreu sem causar grande desestruturação social, devido às mudanças culturais incorridas no deslocamento, de pessoas, de pequenas regiões para grandes cidades. Determinados grupos religiosos, como pentecostalismo e umbanda, tornaram-se, em certo período (décadas de 1960 e 70) importantes redes de sociabilidade (CAMARGO, 1961; 1973).

O crescimento econômico de Rio Grande da Serra não acompanhou, na mesma proporção, o crescimento populacional. Um conjunto de fatores contribuiu para isso. Por sua "condição ambiental”, ou seja, possuir 100\% de sua área considerada “Área de Proteção Permanente de Mananciais” (APP), está, desde 1976, sujeita à legislação correspondente. Isso não permitiu a implantação de indústrias na cidade 4 , o que teve impacto no oferecimento de emprego e renda em condições adequadas, obrigando uma parcela a buscar "vagas de trabalho" em

\footnotetext{
${ }^{4}$ Rio Grande da Serra possui, basicamente, duas indústrias de maior importância: a empresa Dura (autopeças) e a empresa Massa Leve (do ramo alimentício).
} 
outras cidades do ABC e na capital paulista. Esse fator lhe cunhou o rótulo de “cidade dormitório", o que, em nossa opinião, necessita ser reavaliado. Se, por um lado, as pessoas ainda "trabalham fora", por outro, demonstram, atualmente, maior vínculo com o município. O comércio, embora tímido quando comparado às outras cidades do $\mathrm{ABC}$, já possibilita considerável consumo interno. Práticas associativas, que com a possibilidade de gerar renda, têm-se constituído na cidade5, entre elas a "Cooperativa de Cambucy" e o "Projeto Fibras da Serra". As duas associações envolvem um “capital ambiental” importante para o município, pois desenvolvem projetos (com o fruto do cambuci e fibras de bananeira) que não agridem, ou agridem em menor intensidade, o meio ambiente (NORONHA, 2010).

Já foram mencionados a escassa indústria e o pequeno comércio. Somandose a isso a baixa arrecadação de impostos (p. ex., IPTU), o resultado é um "orçamento municipal" que torna a cidade muito dependente de verbas estaduais e federais ${ }^{6}$. Nesse sentido, qual é a importância das "instâncias regionais”, criadas na região do Grande $\mathrm{ABC}$, para o desenvolvimento econômico de Rio Grande da Serra? O debate em torno da “discussão regional” realmente faz sentido para todo o conjunto da região?

Na década de 1990, instâncias criadas na região (do ABC), com o objetivo de envolver diversos atores, como Poder Público, sociedade civil, sindicatos etc., tinham a proposta de alavancar o desenvolvimento das sete cidades. Uma experiência, nesse âmbito, já existia: a "Câmara Setorial Automotiva”. Esta envolvia empresas, governo (estadual e federal) e sindicato de trabalhadores metalúrgicos. Um resultado importante, fruto dessa experiência, foi a implantação, em 1995, da "participação nos lucros e resultados” para os trabalhadores no setor automotivo (GARCIA, 2007). Posteriormente, outras instâncias foram criadas, entre elas o “Consórcio Intermunicipal” e a "Câmara Regional do Grande ABC”, todas com o

\footnotetext{
${ }^{5}$ Quando mencionamos que existem práticas associativas, que permitem algum tipo de "capital econômico", não sugerimos que ocorra em um volume suficiente para suprir as necessidades (de emprego e renda) da população, mas ressaltamos que, embora incipientes, elas existem e contribuem para que haja maior valorização da cidade pela própria população.

${ }^{6}$ Segundo a Seade (2012), o PIB do município de Rio Grande da Serra corresponde a 0,59\% do PIB da região do Grande ABC.
} 
propósito de envolver os diversos “atores sociais” (Poder Público, empresas, sindicatos, sociedade civil). O consórcio reúne os sete prefeitos e busca viabilizar mecanismos de coordenação suprapartidária. Entre os assuntos tratados estão: gestão ambiental, gerenciamento/destino de resíduos sólidos, desenvolvimento econômico e aspectos administrativos. A Câmara Regional, por seu turno, tinha por principal proposta contribuir com ações para o desenvolvimento sustentável do Grande ABC (LÉPORE; KLINK; BRESCIANI, 2006).

No que se refere à importância da "articulação regional” 7 para o crescimento do Grande ABC, todas as cidades surgiram em um momento de crise econômica (nacional), transformações nas estruturas produtivas e trabalhistas (LÉPORE; KLINK; BRESCIANI, 2006; GARCIA, 2007) e o crescimento do debate em torno do desenvolvimento sustentável. Além disso, o momento exigia respostas criativas para os problemas que se agravavam com o crescente "êxodo" de empresas para outras regiões, como, por exemplo, o Nordeste e o interior de São Paulo (KLINK, 2001).

Diante da possibilidade da adoção de um posicionamento econômico “neoliberal”, com diminuição, ou flexibilização, de empregos e salários, esses espaços de discussão, ao contrário, concentravam-se na proposta do fortalecimento da indústria e do comércio local, como forma de alavancar, a partir de acordos regionais, o desenvolvimento da região (DANIEL, 1996; LÉPORE; KLINK; BRESCIANI, 2006). Na opinião de Klink (2001), o que foi realizado no ABC foi um passo importante, considerando a pouca "cultura regional” no Brasil.

Diante do exposto, o que se torna, até certo ponto, evidente na tentativa de reunir esforços e agregar valores em uma perspectiva regional é que ela não conseguiu incluir todo o conjunto da região. Afirmamos isso porque nenhum, ou muito pouco, impacto significativo pôde ser verificado para Rio Grande da Serra até o presente momento nos acordos firmados nas instâncias regionais citadas. Isso

\footnotetext{
${ }^{7}$ Entre as "instâncias regionais" criadas, destacamos, ainda, o "Fórum da Cidadania do Grande ABC" e a "Agência de Desenvolvimento Econômico".
} 
corrobora a hipótese de que, mesmo em uma região importante, como o Grande $\mathrm{ABC}$, os espaços periféricos, socialmente constituídos, fizeram-se presentes.

\section{Religião e Capital Simbólico}

Diante do cenário apresentado, ou seja, um, até então, frágil desenvolvimento econômico, e pouca influência das "articulações regionais" no sentido de alterar significativamente a realidade, pergunta-se: Qual é o papel das redes sociais e práticas associativas "religiosas” no município? Que elementos, materiais e simbólicas, agregam à população? Não seria possível reunir, no âmbito desse estudo, um amplo espectro de formulações ou definições acerca do fato social religioso, o que ajudaria na discussão das práticas relacionadas. Assim, abordamos, de forma muito breve, aquelas que indicam ser a "religião" um sistema cultural ou simbólico capaz, a despeito dos limites impostos pelo mundo moderno para gerar significado.

Os últimos cinco séculos marcaram importantes mudanças sociais, econômicas ou políticas (Revolução Industrial, Reforma Protestante, Iluminismo etc.), que contribuíram de forma gradual, mas definitiva, para que a religião se tornasse uma instituição com pouca capacidade de estruturação da sociedade. As instituições religiosas, e seus elementos doutrinários, não mais definem determinados comportamentos, outrora obrigatórios, como, por exemplo, batizar um filho ou se casar na igreja. Também não mais determinam (no máximo tentam influenciar) a construção de normatizações jurídicas, sobretudo no Ocidente.

Isso não significa (e nunca significou) o fim da religião ou qualquer desaparecimento da relação do ser humano com o "sagrado" (PIERUCCI, 1998; BARRERA, 2002). É verdade, contudo, que as pessoas sentem-se, cada vez mais, "autônomas" na forma como constroem sua relação com a multiplicidade de “universos simbólicos” à disposição (BERGER, 2004; HERVIEU-LÈGER, 2008). A 
religião não desapareceu, mas mudou a forma como se posiciona na sociedade. “A religião não se enfraqueceu como força social. Pelo contrário: parece se ter reforçado no período recente. Mas mudou - e muda cada vez mais - de forma” (GEERTZ, 2006).

Diante disso, o que possibilita à religião constituir-se como sistema, ainda, capaz de gerar sentido às pessoas em meio a incontáveis avanços, científicos e tecnológicos, que, em tese, já teriam resolvido muitos dos mistérios humanos? Para discutir o problema, apoia-se na hipótese de um "inabalável” desejo humano de colocar "ordem" no "caos". As narrativas míticas acerca da "criação" do mundo são exemplos de que, desde a Antiguidade, o ordenamento das coisas era necessário para tornar explicável a existência humana. As religiões, detentoras dos mais variados "sistemas cosmogônicos”, buscam tanto construir explicações “plausíveis” para as mais elementares questões humanas, que são o nascimento e a morte, como especulações sobre o “divino” (DURKHEIM, 1989). Tais explicações não se limitam a responder, de maneira convincente, como o mundo foi criado, mas, sobretudo, como "se deve viver" para que ele seja mantido. A “ordem social”, nesse sentido, não passaria de um "reflexo" da ordem sagrada e açambarcante do universo (BERGER, 2004).

Da mesma forma que "ordem" e "caos" são coisas que não se misturam, como também não se misturam, para Durkheim (1989), as dimensões do "sagrado" e do "profano", as sociedades produzem elementos que se opõe. Questões como pobreza, doenças, drogas, criminalidade são, em geral, associadas ao mal e à desordem, em outras palavras, ao caos. O oposto, como prosperidade, saúde etc., relaciona-se ao bem e à ordem. Tal relação determina, em grande medida, a forma como as pessoas se comportam. Dessa forma a religião não apenas é, ao longo do tempo, estruturada em crenças, símbolos, gestos etc., mas, também, apresenta-se como estruturadora de determinados estilos de vida. A relação coerente entre “estilo de vida” e “explicação metafisica” faz da religião, na visão de Geertz (1989, p. 104-105, grifo nosso), um sistema simbólico como nenhum outro, que: 
atua para estabelecer poderosas, penetrantes e duradouras disposições e motivações nos homens através da formulação de conceitos de uma ordem de existência geral e vestindo essas concepções com tal aura de fatalidade que as disposições e motivações parecem singularmente realistas (GEERTZ, 1989, p. 104-105, grifo nosso).

Para Geertz (1989), o termo "disposições" trata da probabilidade de uma pessoa exercer uma atividade em certas circunstâncias, da tendência ou inclinação para realizar certos tipos de atos, para experimentar certos sentimentos em determinadas situações. Atos ou sentimentos possuem, para quem neles crê, uma forma real. Tal noção nos remete à conhecida expressão de Durkheim (1989, p. 493): "O fiel que comungou com seu deus não é apenas homem que vê verdades novas que o incrédulo ignora: é homem que pode mais”.

A religião coloca-se, assim, como portadora de um "capital religioso", que, por não ser necessariamente quantificado ou mensurado, pode ser chamado de “capital simbólico" (BOURDIEU, 1987). Em um tempo no qual nenhuma instituição, detém o monopólio desse capital, ele está à disposição em um variado (e complexo) "mercado religioso". Bourdieu (1987) utiliza-se do termo "mercado" para indicar, de forma homóloga ao "mercado econômico", que o "campo religioso" é um campo em conflito. A disputa em questão é o conjunto de fiéis que está à procura dos "bens simbólicos de salvação".

O diálogo com Bourdieu (1987) tem por objetivo ressaltar que na sociedade moderna, autônoma ao poder religioso, os vínculos do indivíduo com a instituição religiosa são relativamente frágeis (BARRERA, 2001; HERVIEU-LÈGER, 2008), o que resulta, por parte das pessoas, no não impedimento de buscar o "universo religioso" que melhor atende às suas próprias necessidades, sejam elas físicas ou espirituais. Isso, a nosso ver, não minimiza ou diminui a legitimidade da religião como expressão sociocultural. 


\subsection{0 capital simbólico nas redes sociais religiosas}

Vimos, até agora, que a religião pode ser pensada como um "sistema simbólico”. Os símbolos religiosos, por sua vez, articulam, de maneira sui generis, uma “visão de mundo” e um “estilo de vida” (GEERTZ, 1989) capazes de gerar um “capital religioso”, que, por seu turno, é um “capital simbólico” (BOURDIEU, 1987). Como se traduziriam esses conceitos, especialmente o "capital simbólico", em situações cotidianas envolvendo redes sociais e práticas religiosas? As redes sociais, de cunho religioso, são somente capazes de produzir capital religioso?

As redes sociais, mais ou menos formais, ocorrem a partir de múltiplas “interações" entre parentes, vizinhos, amigos, colegas de trabalho, ou mesmo em formas associativas, mais ou menos estruturadas, como, por exemplo, a participação em cultos, missas, sessões espíritas etc. Para que se trate efetivamente de uma "rede", é fundamental que as relações sejam duradouras, permitindo, assim, a formação de vínculos. Quando essas interações ocorrem com frequência, elas passam a possibilitar, mesmo que potencialmente, um arcabouço de bens "materiais" ou "simbólicos". As redes sociais são construídas em diversificados contextos socioeconômicos, mas há que se ressaltar seu peso, positivo, junto à população mais pobre, à medida que contribuem para a obtenção de "favores" nas relações de troca, ou mesmo no acesso às "estruturas de oportunidade” (LOMNITZ, 2001; MARQUES, 2009).

As formulações de Bourdieu (2007a e 2007b) destacam a capacidade das redes sociais para aumentar o capital social dos participantes. Capital social é entendido, aqui, como a soma dos capitais "econômico" e "cultural" de indivíduos ou grupos. Essa ideia reitera o que foi dito, de que ganhos possibilitados nas diversas interações não são apenas materiais, mas, também, culturais ou simbólicos. Alguém que participe de determinada associação e que esteja em situação de desemprego, pode, por exemplo, receber "cestas básicas”, ou alguma ajuda em "dinheiro", o que se traduz em capital econômico. Contudo, essa mesma 
pessoa pode ter acesso, por sua prática associativa, a cursos de "formação profissional", o que lhe aumenta o capital cultural. Esse processo pode, ainda, aumentar-lhe a "autoestima". O “conhecimento" e a "maior valorização de si mesmo" são bens imateriais, portanto, simbólicos.

No caso das práticas religiosas e suas redes (mais ou menos formais ou estruturadas), estas também possibilitam esse arcabouço. Um fiel, ao participar de um grupo religioso, passa a conviver em uma “comunidade”. Aliás, é justamente essa a delimitação conceitual de Durkheim (1989, p. 77) sobre igreja: uma “[...] comunidade moral formada por todos os crentes da mesma fé”. Participar durante um longo período de um grupo pode, em situações de necessidade, resultar em algum tipo de ajuda. Esta pode ser material, contudo, esse não é o principal objeto deste estudo. Desejamos pôr em relevo aquilo que não é tangível, mensurável ou quantificável, mas que é possibilitado pelas práticas religiosas.

Como dito, a religião faz a ponte entre uma "visão de mundo" e um "estilo de vida". Isso torna a visão de mundo um conjunto de crenças e práticas, algo "real" para os que creem e praticam. A crença, no batismo e nos dons, do "Espírito Santo" faz do crente, tocado por Ele, alguém que recebeu o poder de Deus. É possível, segundo a força da fé, que a cura prometida por um “preto velho”, em uma sessão de umbanda, tenha "força maior" do que um tratamento na medicina tradicional, mesmo que, em certos casos, o indivíduo em questão saiba que dependerá de tal instituição, no plano material, para realizar o que foi prometido no espiritual.

Cura, emprego, libertação das drogas, ou mesmo "salvação" e "iluminação" são elementos "materiais" e "simbólicos" que, por vezes, misturam-se no emaranhado de coisas que as pessoas buscam na religião. Contudo, nem sempre basta querer um emprego, ou querer resolver um problema familiar. É preciso ter a "força espiritual" e, muitas vezes, a "autoestima” para conseguir. Esses são elementos pouco mensuráveis, mas que se destacam nos relatos daqueles que afirmam tem alcançado algum tipo de "graça divina”. 
É o que constata Mesquita (2009) em uma favela no Campo dos Goytacazes, no Rio de Janeiro, aos estudar fiéis pertencentes às igrejas pentecostais. Na "batalha espiritual” entre os fiéis e o tráfico, os primeiros valorizam a "proteção” e a "unção divina", construindo uma autoimagem que os investe de uma "valorização moral”. "O que esses pentecostais reforçam são as identificações baseadas por conjunto de experiências sociais e religiosas que os colocam em distinção moral com relação àqueles que estão no tráfico” (MESQUITA, 2009, p. 98). Em uma perspectiva "missionária cristã", os apontamentos de Grigg (2008) relatam a importância de uma "crença religiosa” para habitantes de favelas nas Filipinas. O autor constatou, em seus muitos anos de missão, que o pertencimento (movido pela fé) a um grupo religioso pode retirar pessoas das drogas, da prostituição etc.

No que diz respeito às lideranças religiosas, sua trajetória, no interior das instituições, permite-lhes administrar um conjunto de "bens religiosos". Se usarem bem seu carisma, respeitando regras e tradições ou colocando-se "pessoalmente" como um canal do poder divino (como no caso do pentecostalismo), ganham a "legitimidade" necessária para se manter na posição em que estão, ou galgar novas responsabilidades dentro da instituição (WEBER, 1996). Esse "reconhecimento" ou “prestígio” é, também, uma forma de capital simbólico (BOURDIEU, 1987).

Por fim, quando pensamos em associações religiosas mais estruturadas em torno de "projetos específicos", como assistência a crianças, por exemplo, quais seriam os capitais possibilitados em sua participação? No próximo tópico trata-se especificamente dessa questão, quando são analisadas as atividades produzidas pelo “Projeto Social Pequeno Samuel”. Como destacado, Rio Grande da Serra está inserida em uma área de proteção de mananciais. Nesse caso, além daquilo que comumente poderíamos incluir como "ganhos" importantes para uma população carente, como é o caso desse município, entendemos que a manutenção do "capital ambiental" da cidade - como sua vegetação e seus recursos hídricos - é, no contexto que estamos analisando, uma espécie de capital simbólico. Isso porque o "meio ambiente" constitui-se mais que o ambiente natural, está interligado a um 
conjunto de aspectos sociais, econômicos, políticos etc. (GUERRA, 2009).

\section{Projeto Social Pequeno Samuel}

São descritas, aqui, as principais atividades do Projeto Social Pequeno Samuel (PSPS). Em seguida, realiza-se uma reflexão sobre os principais benefícios de sua participação. As informações foram obtidos através do site da entidade (PSPS, 2012), de seu estatuto e de registros em caderno de notas durante observações presenciais.

O PSPS, projeto social apoiado pela Igreja Batista Central, é uma entidade sem fins lucrativos iniciada, em 2004, pelos missionários Paulo J. Ferreira e Estela V. Ferreira. Entre seus objetivos estão desenvolver atividades que ajudem a diminuir o abuso infantil e a violência doméstica ${ }^{8}$, difundir diretos dos cidadãos, combater a desigualdade social e realizar campanhas de combate às drogas. Nesse sentido, promovem atividades educativas e cultuais. Entre elas estão:

- Projeto Sócio-Educativo PEPE: o objetivo é o atendimento socioeducacional e espiritual a crianças de 4 a 6 anos e suas famílias. Além de ser um espaço no qual as crianças podem ficar em maior segurança durante uma parte do dia, contribuiu para melhorar o desempenho escolar, além do processo de socialização e cidadania. O conteúdo trabalhado no projeto envolve cuidado com saúde, higiene, além da preservação do meio ambiente e cuidado com os animais. Também é realizado um acompanhamento familiar para identificar as principais necessidades da casa.

\footnotetext{
${ }^{8}$ A questão da "violência domestica" é uma preocupação na cidade devido, principalmente, ao crescimento do uso de drogas e bebidas alcoólicas. Isso porque o indivíduo, quando em estado alterado (pela bebida ou pela droga) pode tornar-se muito violento, descontando, em muitos casos, suas frustrações na mulher e nos filhos, o que tem ocorrido com frequência em Rio Grande da Serra (NORONHA, 2011). Quando da comemoração do "Dia das Mães" e "Dia dos Pais", o projeto realiza palestras para orientar os "pais" sobre uma melhor educação com os filhos, evitando atitudes violentas por parte daqueles.
} 
- Projetos esportivos/aulas de jiu-jitsu: as aulas de jiu-jitsu, entre outras atividades esportivas, têm, no PSPS, o objetivo de melhorar o desenvolvimento físico da criança e do adolescente e de ensinar conceitos de disciplina e respeito, como forma de diminuir a violência de rua e propiciar um espaço de ocupação e lazer. Segundo os coordenadores, há certo preconceito em relação a essa "arte marcial”, devido seu caráter “violento”. Entretanto, reforçam que o processo é justamente o inverso. Explicam que, para prosseguir na “caminhada” dentro do jiu-jitsu, não podem brigar na rua ou na escola.

- Aulas de artesanato/pintura em tecido: as aulas de artesanato e pintura em tecido têm a finalidade de contribuir para a geração de renda. Nesse caso, o capital não é apenas cultural (conhecimento sobre a técnica de artesanato e pintura), mas aumenta o potencial de geração de capital econômico, visto que o aprendizado possibilita a produção e a venda do produto.

- Curso de inglês: as aulas de inglês têm o objetivo tanto de contribuir para o reforço de possíveis deficiências no ensino escolar (que, em geral, são muitas) como estimular os jovens a aperfeiçoar o idioma, este, ainda, uma ferramenta importante em aspectos profissionais.

- Educação para práticas ambientais: esse projeto ainda está dando seus primeiros passos no PSPS, contudo, é importante citá-lo, pois tem relação com aspectos ambientais, um capital importante para o município e sua população 9 . O projeto conta com a colaboração de um "gestor ambiental”, morador da cidade (SCARPIONI, 2012). O objetivo principal é instrumentalizar as pessoas envolvidas para a difusão dos conceitos e práticas ambientais na comunidade. Quanto aos objetivos específicos, pretende-se implementar as seguintes práticas: 1) um sistema de gestão ambiental interno; 2) promover debates na instituição

\footnotetext{
${ }^{9}$ Segundo a ONG SOS Mata Atlântica, Rio Grande da Serra é a única cidade da Região Metropolitana de São Paulo que ainda possui $77 \%$ de mata remanescente preservada (SERRANO, 2007).
} 
e na comunidade sobre as necessidades ambientais locais; 3) realizar mutirões e caminhadas ecológicas; e 4) promover coleta seletiva de materiais recicláveis e não recicláveis, embasadas nos chamados 3 Rs (reduzir, reutilizar e reciclar). Em 02/06/2012 (data próxima ao Dia Mundial do Meio Ambiente) foi realizada a primeira atividade de "conscientização ecológica" organizada pelo PSPS, dirigida pelo "gestor ambiental”. Nessa ocasião, os jovens passearam pelo bairro (Santa Tereza), observando aspectos de "degradação ambiental” e recebendo informações sobre como se portar diante de tais situações (PSPS, 2012).

O resultado almejado com este trabalho é despertar, sensibilizar e incentivar de maneira efetiva as pessoas para as questões ambientais, pois é preciso aumentar o grau de consciência de todos diante da conservação e preservação do ambiente natural e, também, do artificial. Isso porque o fato de o lixo ser jogado nas vias de maneira indiscriminada contribui para a perda de qualidade ambiental, deprecia esteticamente o local, contamina e polui os rios, contribui para enchentes e tantos outros problemas ambientais consecutivos.

Por esse conjunto de fatores, considera-se o PSPS um projeto importante para a população local. O bairro Santa Tereza, onde está localizado, possui uma parte de sua população em situação precária, embora, segundo os responsáveis, participem do projeto crianças de muitos bairros da cidade. Aparentemente, a estada dos jovens durante uma parte do dia, por si só, já se mostra relevante, pois evita que fiquem "perambulando" pelas ruas, o que é a realidade de muitos, e passam a ter acesso a diversas atividades, como os cursos (artesanato, pintura, inglês), que contribuem, em alguma medida, para o aumento de seu capital cultural.

O projeto ambiental é considerado de grande importância, porque, apesar de ser uma área de proteção ambiental, a cidade possui muitos problemas, entre eles: 
1) Falta de saneamento básico em determinados locais (há necessidade de aumento da rede coletora de esgoto e da rede de drenagem de águas pluviais; ampliação da coleta de lixo nos bairros; conservação e melhoria das vias públicas).

2) Faltam projetos de educação ambiental que estimulem coleta seletiva, horta comunitária, ampliação da difusão histórica e turística da região (hoje restrita ao Festival do Cambuci).

3) É necessária maior fiscalização para o controle de desmatamento sem licenciamento ambiental e o controle de loteamentos clandestinos e irregulares.

4) Também se faz necessária maior manutenção dos rios que, atualmente, recebem esgoto in natura de toda a cidade sem qualquer forma de tratamento.

\section{Conclusão}

As redes sociais e as práticas associativas, no campo religioso, proporcionam aos seus participantes mais do que um conjunto de "bens materiais", ou, se preferirmos, um montante de capital econômico. Proporcionam, antes de tudo, outro tipo de capital, o simbólico, nesse caso, menos quantificável que os ganhos materiais, contudo, não menos significativo.

Em espaços religiosos, como cultos, missas, sessões etc., os indivíduos recebem elementos como "força espiritual" ou "autoestima", ou tantas outras coisas, como esperança em uma vida melhor, possibilidade de cura, fé na obtenção de um novo emprego etc. São questões pouco legítimas? Como julgar a importância dessas coisas, tão particulares, para alguém? Como negar, por exemplo, o poder e a força das "orações" ou dos "louvores", nos cultos pentecostais, que falam de "vitórias" e "transformações"? Sem dúvida, são arcabouços simbólicos que se constroem com enorme força e realidade para aqueles que creem. Do mesmo modo 
que os demais elementos "intangíveis", o capital cultural ou ambiental também é um capital simbólico.

Nesse sentido, projetos sociais, como o "Pequeno Samuel", constituem-se como importantes para a população mais carente, justamente porque possibilitam aos participantes (em grande parte, crianças e adolescentes) um ganho que transcende o capital econômico. Proporcionam não apenas o aumento do "capital cultural”, através de cursos (reforço escolar, inglês, artesanato) ou do "capital ambiental”, através da preservação de sua cidade pela educação ecológica, mas, também, "autoestima”, "cidadania” e sentimento de pertença a um grupo ${ }^{10}$. Por fim, concluímos que as práticas associativas religiosas transcendem aquilo que poderia ser seu próprio universo, proporcionando aos seus membros um "capital” simbólico que não passa, somente, por um capital religioso.

\section{REFERÊNCIAS}

BARRERA, P. Tradição, transmissão e emoção religiosa: sociologia do protestantismo contemporâneo da América Latina. São Paulo: Olho d'água, 2001.

BARRERA, P. Desencantamento do mundo e declínio dos compromissos religiosos: a transformação religiosa antes da pós-modernidade. Revista Ciências Sociais e Religião, Porto Alegre, ano 4, n. 4, p.87-104, out. 2002.

BERGER, P. A Suposta Morte do Sobrenatural. In: BERGER, P. Um rumor de anjos. Petrópolis: Vozes, 1974. Cap. 1, p.13-45.

BERGER, P.O dossel sagrado: elementos para uma teoria sociológica da religião. 5. ed. São Paulo: Paulus, 2004.

BOURDIEU, P. A Distinção: crítica social do julgamento.. São Paulo: Edusp; $2007 a$.

BOURDIEU, P. A Economia das trocas simbólicas. São Paulo: Perspectiva, 1987.

\footnotetext{
${ }^{10}$ Em certo sentido, cumprem um papel que deveria ser do Estado. Contudo, pela complexidade do tema e pelo limite que o espaço nos impõe, não é possível aprofundar essa questão.
} 
BOURDIEU, P. The forms of capital. In: J. Richardson (Ed.) Handbook of Theory and Research for the Sociology of Education. New York: Greenwood, 1986, p.241-258.

BOURDIEU, P. Razões práticas: sobre a teoria da ação. 8. ed. Campinas: Papirus, $2007 \mathrm{~b}$.

CALDEIRA, T. P. R. Cidade de muros: crime, segregação e cidadania em São Paulo. São Paulo: Ed. 34, 2000.

CAMARGO, C. P. F. Kardecismo e umbanda: uma interpretação sociológica. São Paulo: Pioneira, 1961.

CAMARGO, C. P. F. Católicos, protestantes, espíritas. Petrópolis: Vozes, 1973.

DAMIANI, A. L. Urbanização crítica e situação geográfica a partir da metrópole de São Paulo. In: CARLOS, Ana F. A.; OLIVEIRA, Ariovaldo U. (Org.). Geografias de São Paulo, São Paulo: Contexto, 2004. Cap. 1, p. 19-58.

DANIEL, C. Uma estratégia econômica para o Grande ABC. São Paulo em Perspectiva, São aulo, v.10, n. 3, p.138-144, jul./set. 1996.

DURKHEIM, E. As formas elementares da vida religiosa: o sistema totêmico da Austrália, São Paulo: Paulinas, 1989.

FONTES, P. Um nordeste em São Paulo: trabalhadores migrantes em São Miguel paulista (1945-66). Rio de Janeiro: Ed. FGV, 2008.

FRENCH, J. D. O ABC dos operários: conflitos e alianças de classe em São Paulo, 19001950. São Caetano do Sul: Hucitec, 1995.

FUNDAÇÃO SISTEMA ESTADUAL DE ANÁLISE DE DADOS. Perfil municipal. Disponível em: <http://www.seade.gov.br/produtos/perfil/perfilMunEstado.php>. Acesso em: 20 jul. 2012.

GARCIA, I. As operárias do ABC: reestruturação produtiva, relações de gênero e participação sindical feminina nos anos 1990. Santo André: Ed. Do Autor, 2007.

GEERTZ, C. A Interpretação das culturas. Rio de Janeiro: Guanabara Koogan, 1989.

GEERTZ, C. O futuro das religiões. Folha de São Paulo, São Paulo, 14 maio 2006.

GRIGG, V. Servos entre os pobres: Cristo nas favelas urbanas. Viçosa: Ultimato, 2008.

GUERRA, C. B. Os saberes ambientais e a governança das águas. Horizonte, Belo Horizonte, v.7, n.14, p.93-113, jun. 2009.

HERVIEU-LÈGER, D. O peregrino e o convertido: a religião em movimento. Petrópolis: Vozes, 2008. 
INSTITO BRASILEIRO DE GEOGRAFIA E ESTATÍSTICA. Censo demográfico 2o1o: religião - amostra. Disponível em: <http://www.ibge.gov.br/cidadesat/

topwindow.htm?1>. Acesso em: 20 jul. 2012.

KLINK, J. J. A cidade-região: regionalismo e reestruturação no Grande ABC paulista. Rio de Janeiro, DP\&A, 2001.

LÉPORE, W. C.; KLINK, J. J.; BRESCIANI, L. P. Câmara Regional do Grande ABC produção e reprodução do capital social na Região do Grande ABC Paulista. Revista Economia e Gestão, Belo Horizonte, v.6, n.13, p.42-45, 2006.

LOMNITZ, L. A. Redes sociales, cultura y poder: ensayos de antropología latinoamericano. México: Flasco, 2001.

MARQUES, E. As redes sociais importam para a pobreza urbana? Dados: Revista de Ciências Sociais, Rio de Janeiro, v. 52, n. 2, p. 471-505, 2009.

MARQUES, E.; TORRES, H. São Paulo: segregação, pobreza e desigualdades sociais. São Paulo: Ed. Senac, 2004.

MESQUITA, W. Os pentecostais e a vida em favela no Rio de Janeiro. Estudos de Religião, São Bernardo do Campo, v.23, n.37, p.89-103, jul./dez. 2009.

NORONHA, C. P. Religião e capital social na periferia urbana do Grande ABC Paulista: uma análise das redes sociais pentecostais no município de Rio Grande da Serra. 2010.177 f. Dissertação (Mestrado em Ciências da Religião) - Faculdade de Humanidades e Direito, São Bernardo do Campo.

NORONHA, C. P. Redes sociais pentecostais e [dependência química] no município de Rio Grande da Serra, no Grande ABC paulista. Sacrilegens, Juiz de Fora, v.8, n.1, p.148-163, 2011.

PIERUCCI, A. F. Secularização em Max Weber: da contemporânea serventia de voltarmos a acessar aquele velho sentido. Revista Brasileira de Ciências Sociais, São Paulo, v.13, n.37, p. 43-73,1998.

PROJETO SOCIAL PEQUENO SAMUEL - PSPS. Estatuto da entidade. Disponível em: <www.projetopequenosamuel.org.br>. Acesso em: 20 jul. 2012.

SANTOS, M. O espaço dividido: os dois circuitos da economia urbana dos países subdesenvolvidos. Rio de Janeiro: Francisco Alves, 1979.

SANTOS, M A urbanização brasileira. São Paulo: Edusp, 2008.

SCARPIONI, M. M. S. Consultoria ambiental: gestão ambiental e trânsito. Disponível em: <http://marcosscarpioni.wix.com/gestao\#!gestao-ambiental>. Acesso em: 20 jul. 2012. 
SERRANO, M. R. (Org.). O desenvolvimento socioeconômico de Rio Grande da Serra. São Paulo: Publisher Brasil, 2007.

SINGER, P. Economia política da urbanização. 2. ed. São Paulo: Contexto, 2002.

WEBER, M. Economia y sociedad: esbozo de sociologia comprensiva, 2.ed. Ciudad del México: Fondo de Cultura Economica, 1996. 